\title{
Marco Común de REFERENCIA Y DERECHO DE OPCIÓN DEL ACREEDOR EN EL INCUMPLIMIENTO CONTRACTUAL
}

\author{
A Common Frame of Reference \\ AND THE CREDItOR'S Option IN \\ BREACH OF CONTRACT
}

\section{Quadro Comum de Referência e DIREITO DE OPÇÃO DO CREDOR NO INCUMPRIMENTO CONTRATUAL}

JOSÉ MAXIMILIANO RIVERA-RESTREPO*

* $\quad$ orcid.org/0000-0003-0422-8494. Universidad Gabriela Mistral, Chile. jose.rivera@ugm.cl

RECIBIDO: 12 DE ENERO DE 2016. ENVÍO A PARES: 13 DE JULIO DE 2016. APRobado Por PARES: 21 dE SEPTIEMBRE DE 2016. ACEPTAdo: 22 DE SEPTIEMBRE DE 2016.

DOI: $10.5294 / D I K A .2016 .25 .2 .6$

PARA CITAR ESTE ARTÍCULO / TO REFERENCE THIS ARTICLE / PARA CITAR ESTE ARTIGO Rivera-Restrepo, José MAXIMILIANo. "MARCo Común de REFERENCIA y DERECHO dE OPCIÓN DEL ACREEDOR EN EL INCUMPLIMIENTO CONTRACTUAL”, EN DIKAION, 25, 2 (2016), 


\section{RESUMEN}

En esta investigación se plantean algunos atisbos en torno al llamado Proyecto de Marco Común de Referencia, para luego analizar, desde una perspectiva crítica, la regulación que otorga respecto al derecho de opción del acreedor en el incumplimiento contractual.

\section{PALABRAS CLAVE}

Derecho de opción; resolución; incumplimiento contractual; derecho de remedios; Marco Común de Referencia. 


\section{ABSTRACT}

This study looks at the so-called Draft Common Frame of Reference and critically analyzes the rule it affords concerning the creditor's option in breach of contract.

\section{KEYWORDS}

Option right; resolution; breach of contract; right to remedies; Common Frame of Reference. 


\section{RESUMO}

Nesta pesquisa, propõem-se alguns vislumbres em torno do chamado Projeto de Quadro Comum de Referência, para depois analisar, a partir de uma perspectiva crítica, a regulação que outorga com relação ao direito de opção do credor no incumprimento contratual.

\section{PALAVRAS-CHAVE}

Direito de opção; direito de remédios; incumprimento contratual; Quadro Comum de Referência; resolução. 
SUMARIO: INTRODUCCIÓN; 1. ANTECEDENTES; 2. REgulACIÓN DEL DERECHO DE OPCIÓN DEL ACREEDOR EN EL MARCo COMÚN DE REFERENCIA (THE DRAFT COMMON FRAME OF REFERENCE); 2.1. LA RESOLUCIÓN DEL CONTRATO POR INCUMPLIMIENTO; 2.2. EL CUMPLIMIENTO FORZADO DE LA OBLIGACIÓN; 2.3. LA PARALIZACIÓN DEL CUMPLIMIENTO DEL CONTRATO; 2.4. LA REDUCCIÓN DEL PRECIO; 2.5. LA INDEMNIZACIÓN DE DAÑOS Y PERJUICIOS; CONCLUSIÓN; BIBLIOGRAFÍA.

\section{INTRODUCCIÓN}

En este artículo nos proponemos revisar, primeramente, y de forma tangencial, la historia fidedigna del establecimiento del Proyecto de Marco Común de Referencia (MCR), para luego analizar el tema principal de este trabajo: la regulación que el MCR otorga respecto del derecho de opción del acreedor ante el incumplimiento contractual. Es interesante esta referencia académica, toda vez que ella representa parte del alma europea en materia de contratos. Una cierta visión de la realidad $\mathrm{y}$ del derecho, que debe ser tenida a la vista a la hora de uniformar y armonizar el derecho europeo de contratos. Interesa, sobre todo, estudiar los principios y las instituciones que sustentan esta propuesta, para establecer la conveniencia o no de acogerla.

\section{Antecedentes ${ }^{1}$}

En el marco del proceso de armonización y unificación del derecho europeo de los contratos $^{2}$ aparecen, en el último tiempo, según la opinión general de la doctrina, dos hitos relevantes: la aprobación de la Directiva 2011/83/EU sobre derecho de los consumidores y la publicación del proyecto de Reglamento sobre un derecho común de la compraventa ( $1^{\circ}$ de julio de 2010), usualmente llamado "Instrumento Opcional" ${ }^{3}$ Conforme al Libro Verde sobre opciones politicas para avanzar hacia un derecho contractual europeo en materia de consumo y derecho de las empresas, que sustentaría un Marco Común de Referencia (DCFR, por sus siglas en inglés), ${ }^{4}$ preparado por $\mathrm{CoPECL}^{5}$ y revisado por un grupo de trabajo creado el 26

$1 \quad \mathrm{Al}$ respecto, véase J. Basedow, K. J. Hopt, R. Zimmermann, A. Stier (eds.), The Max Planck Encyclopedia of European Private Law, vols. I y II, Published under the auspices of the Max Planck Encyclopedia of European Private Law, Oxford, Oxford University Press, 2012, pp. 261-265.

2 I. Gallego Domínguez, "La unificación del Derecho civil patrimonial europeo", en J. M. GonzÁlez Porras, F. P. Méndez González (coords.), Libro Homenaje al profesor Manuel Albaladejo García, T. I, Murcia, Colegio de Registradores de la Propiedad y Mercantiles de España, Servicio de Publicaciones de la Universidad de Murcia, 2004, pp. 1787-1810.

$3 \mathrm{Al}$ respecto, véase E. FERNÁNDEZ MASIÁ, "Optando por la normativa común de compraventa europea”, en Revista Electrónica de Estudios Internacionales, 2012, pp. 1-21, en http://www.reei.org, fecha de consulta: 05 de mayo de 2013.

4 En este sentido, vON BAR señala que: "And there are, on our side, other connected with the drafting of a 'Common Frame of Reference'. One is that for the first time for approximately 200 years students from all over Europe could be taught parts of the law in all European universities on the basis of an identical text. Whether they go to Uppsala, Edinburgh, Budapest or Amsterdam, they could be sure that for at least one or two terms they would study there exactly what they would have studied at home". C. vON BAR, "A Common Frame of Reference for European Private Law-Aca-

demic Efforts and Political Realities", en V. V. PALmer (ed.), The Tulane European and civil law forum,
vol. 23, New Orleans, Tulane University School of Law, 2008, p. 38.
$5 \quad$ Al respecto, Rutgers señala que: "Como es sabido, el DFCR se elaboró fruto de la colaboración entre

demic Efforts and Political Realities", en V. V. PALMER (ed.), The Tulane European and civil law forum,
vol. 23, New Orleans, Tulane University School of Law, 2008, p. 38. un grupo de profesores universitarios -la Joint Network on European Law (CoPECL)-, por invitación 
de abril de $2010,{ }^{6}$ encargado de revisar y elegir aquellas partes que, directa o indirectamente, se relacionen con el derecho de los contratos. ${ }^{7}$ Por otra parte, se le encomendó reestructurar y completar las normas seleccionadas. Poco más de un año de trabajo, en agosto de 2011, se dio a conocer la "Feasibility study on a future iniciative on European contrac law” (en adelante FS), que más tarde vendría a constituir el Instrumento Opcional. ${ }^{8}$

El Proyecto del MCR se debe a las comunicaciones de la Comunidad Europea y a las resoluciones del Parlamento, ${ }^{9}$ a partir de la Comunicación de 2001 sobre el derecho contractual europeo. ${ }^{10}$ En 2003, la Comisión presentó un Plan de Trabajo, mediante la expedición de la Comunicación de 12 de febrero de $2003,{ }^{11}$ cuya finalidad era incrementar la armonía en materia de derecho contractual europeo. ${ }^{12}$ Esta Comunicación introdujo la idea de "marco de referencia", debiendo presentar el mejor elenco de conceptos abstractos y reglas comunes. Por su parte, la Comunicación de 11 de octubre de 2004, llamada "Derecho contractual europeo y revisión del acervo: perspectivas para el futuro”, determina cómo se construirá un marco común de referencia. ${ }^{13}$ La primera versión de MCR

de la Comisión Europea y ha sido financiada dentro del 6. ํ Programa de Investigación de la Red”. J. W. Rutgers, "Los contratos de agencia, franquicia y distribución en el DCFR", en E., Bosch CAPdevila (dir.), Decanato del Colegio de Registradores de Cataluña (coord.), Derecho contractual europeo. Problemática, propuestas y perspectivas, Barcelona, Bosch, 2009, p. 312.

6 En este sentido, Vaguer Aloy señala que: "El Marco Común de Referencia [...], con una denominación creada ad hoc y que no se identifica con el instrumento codicial, expresamente rechazado por la Comisión Europea, carece de entrada de ese atractivo". A. VAguer Aloy, "El Marco Común de Referencia”, en E. Bosch Capdevila (dir.), Derecho contractual europeo. Problemática, propuestas y perspectivas, op. cit., p. 240.

$7 \quad$ El MCR fue planteado por la Comisión Europea en 2003, como una de las maneras de superar la diversidad jurídica existente en Europa. I. Miláns del Bosch Portolés, "Cumplimiento e incumplimiento del contrato internacional”, en X. O’CAllaghan Muñoz (coord.), Cumplimiento e incumplimiento del contrato, Madrid, Universitaria Ramón Areces, 2012, pp. 683-684.

8 A. Vaguer Aloy, E. Bosch Capddevila, Ma . P. Sánchez González, "Prólogo", en A. Vaguer Aloy, E. Bosch Capddevila, Ma . P. Sánchez González (coords.), Derecho europeo de contratos. Libros II y IV del Marco Común de Referencia, T. I, Barcelona, Atelier Libros Jurídicos, 2012, p. 71.

$9 \mathrm{Al}$ respecto, véase M. Medina ORTEGA, "El Derecho patrimonial europeo en la perspectiva del Programa de Estocolmo", en J. C. FERnández Rozas (dir.), Anuario español de Derecho internacional privado, t. X, Marcial Pons, Ediciones Jurídicas y Sociales, Madrid, 2010, pp. 84-87.

10 En este sentido, Arroyo i Amayuelas expresa lo siguiente: "En la redacción del citado MCR están implicados varios grupos de investigación, integrados por juristas de distintos países, que cuentan con la financiación que ofrece la red de excelencia 'CoPECL', que los agrupa a todos". E. ARroyo I Amayuelas, "Hacia un derecho contractual más coherente: La sistematización del acervo contractual comunitario", en E. Bosch Capdevila (dir.), Decanato del Colegio de Registradores de Cataluña (coord.), op. cit., p. 211.

11 E. Valpuesta Gastaminza, "La propuesta de Derecho privado unificado de obligaciones y contratos para Europa: el Draft Common Frame of Reference", en E. ValPuesta Gastaminza (coord.), Unificación del Derecho patrimonial europeo. Marco Común de Referencia y Derecho español, Barcelona, Bosch, 2011, p. 66.

12 En este sentido, De la CuEsta Rute señala que: "El proyecto es el fruto de un 'plan de acción' establecido por la Comunicación de la Comisión al Parlamento y al Consejo de 12 de febrero de 2003". J. Ma . De la Cuesta Rute, "Sobre la unificación del Derecho privado patrimonial en Europa”, en E. Valpuesta Gastaminza (coord.), Unificación del Derecho patrimonial europeo. Marco Común de Referencia y Derecho español, op. cit., p. 23.

13 Vaguer Aloy,, "El Marco Común de Referencia”, op. cit., pp. 240-241. 
apareció en 2007, en $2009^{14}$ se publica la segunda versión de los mismos. ${ }^{15}$ Posteriormente, se editó una full edition, que consta de seis tomos, un comentario $\mathrm{y}$ algunas notas en torno a los derechos nacionales. ${ }^{16} \mathrm{El} \mathrm{MCR}{ }^{17}$ no tiene por finalidad ser un código, ${ }^{18}$ sino, como lo indica su nombre, servir de "referencia" 19 académica $^{20}$ para la expedición de sentencias y leyes en el ámbito que indica, ${ }^{21}$ aun cuando no se sabe en qué clase de fuente formal se convertirá. ${ }^{22}$ Además, podría ampliarse el radio de acción del MCR y no solo acotarlo a la materia que se refiere (derecho del consumo). ${ }^{23}$

14 Para los autores Eidenmüller, et al.: "A comienzos del año 2008 cuando se presentó el Proyecto de un marco común de referencia para el Derecho privado europeo”. H. Eidenmüller, F. FAust, H. C. Grigoleit, N., Jansen, G. Wagner, R. Zimmermann, El marco común de referencia para el Derecho privado europeo. (Cuestiones valorativas y problemas legislativos), en ADC, t. LXII, fasc. IV, Madrid, 2009, p. 1461. M., MeLI, "Proposta di Regolamento - Diritto comune europeo della vendita", Le nuove legi civil commentate, anno XXXV, núm. 1 gennaio-febbraio, Milano, Wolters Kluwer Italia S. R. L., Centro Direzionale Milanofiori, 2012, p. 191.

15 Al respecto, véase F. Redondo Trigo, "De los Principios Lando al Marco Común de Referencia del Derecho Privado Europeo. Hacia un nuevo ius commune", en Ministerio DE Justicia (Centro de Publicaciones) y Boletín Oficial del Estado (eds.), Anuario de Derecho civil, t. LXIII, fasc. IV, octubrediciembre, Madrid, Librería del Boletín Oficial del Estado, 2008, p. 1662.

16 De la Cuesta Rute, "Sobre la unificación del Derecho privado patrimonial en Europa”, op. cit., pp. 24-25.

17 El MCR es, en palabras de LeIBLE: “[...] sobre todo un documento accesible al público que ayudaría a los organismos comunitarios a configurar de forma coherente el Derecho privado europeo existente y futuro en el marco del Derecho europeo de los contratos. Y parece que el Consejo tiene en estos momentos unas ideas parecidas". S. Leible, "El Marco Común de Referencia y la elección del Derecho aplicable”, en J. C. FERnández Rozas (dir.), Anuario español de Derecho internacional privado, t. VIII, Madrid, Marcial Pons, Ediciones Jurídicas y Sociales, 2008, p. 484.

18 En este sentido, ZimmERMAnN señala que: "The DCFR is supposed to mark the apogee of all European legal harmonization efforts". Zimmermann, R., “The Present State of European Private Law”, en M. W. REImAnn (ed.), The American Journal of comparative law 57 (2) (2009), p. 490.

19 Al respecto, Medina Ortega señala que: "En 2004 la Comisión se pronuncia a favor de un instrumento no vinculante, es decir, de Derecho indicativo. El MCR sería solo una "herramienta para presentar propuestas de mejora de la cantidad y calidad del acervo actual y de los futuros instrumentos jurídicos en el ámbito del Derecho contractual”. Medina OrTEGA, "El Derecho patrimonial europeo en la perspectiva del Programa de Estocolmo", op. cit., p. 85.

20 ArRoyo i Amayuelas expresa lo siguiente: "[El MCR], cuyos objetivos son la definición precisa de los términos jurídicos, la enunciación de principios fundamentales y la formulación de reglas del Derecho de contratos inspiradas tanto en el acquis communitaire como en las regulaciones de los ordenamientos jurídicos de los diferentes Estados Miembros”. E. Arroyo i Amayuelas, "Los Principios del Derecho contractual comunitario. Prólogo", en Ministerio de Justicia (Centro de Publicaciones) y Boletín Oficial del Estado (eds.), Anuario de Derecho civil, t. LXI, fasc. I, enero-marzo, Madrid, Librería del Boletín Oficial del Estado, 2008, p. 211.

21 En este sentido, De la Cuesta Rute expresa lo siguiente: "El proyecto de marco de referencia se expresa mediante principios, normas y definiciones. Y, aunque los principios se recogen en lo que en un texto normativo propiamente dicho constituiría su exposición de motivos o preámbulo y las definiciones en un anexo, lo cierto es que, careciendo por ahora de valor normativo y situados en el contexto del proyecto, hay que conceder la misma importancia a las tres categorias de principios, normas y definiciones". De la Cuesta Rute, “Sobre la unificación del Derecho privado patrimonial en Europa", op. cit., p. 31.

22 Sobre este punto, VAgUer Aloy señala que: "En primer lugar, hay que tener muy en mente que lo que se ha presentado a la Comisión y al debate público no es más que el llamado ' $C F R$ académico', esto es, el documento elaborado por la red CoPECL, y que no tiene por qué ser adoptado en bloque por la Comisión. Es evidente que el 'CFR académico' sobrepasa los límites del encargo concebido por la Comisión originariamente, aunque eso ya se sabía desde un principio". VAguer Aloy, "El Marco Común de Referencia", op cit., p. 245. Con relación al carácter "académico" del MCR, véase DE LA Cuesta Rute, "Sobre la unificación del Derecho privado patrimonial en Europa", op. cit., pp. 28-29.

23 Vaguer Aloy, "El Marco Común de Referencia”, op. cit. pp. 243-244. 
Los principales fines del llamado Marco Común de Referencia son: elaborar un conjunto de reglas jurídicas coherentes y armónicas, que puedan servir de modelo ${ }^{24}$ para la expedición de leyes nacionales en el ámbito europeo, ${ }^{25}$ y servir de base ${ }^{26}$ para la expedición de un texto común, de carácter facultativo, en materia de contratos. ${ }^{27}$ En este sentido, el MCR se ha tratado de definir como un conjunto de reglas (principios) modelo ${ }^{28}$ en materia de derecho contractual, ${ }^{29}$ que ha permitido superar los defectos de la actual regulación en esta materia. ${ }^{30} \mathrm{El} \mathrm{MCR}$, a diferencia de los Principios de Derecho Europeo de los Contratos (PECL), tiene una marcada tendencia económica, ${ }^{31}$ mientras los Principios presentan una tendencia más social. ${ }^{32}$ Así,

24 En este sentido, Eidenmüller et al., señalan que: "el Parlamento europeo promueve desde hace ya tiempo la adopción de un texto de referencia ratione imperii, es decir, una vía de una codificación europea del Derecho civil". Eidenmüller, Faust, Grigoleit, Jansen, Wagner y Zimmermann, El marco común de referencia para el Derecho privado europeo. (Cuestiones valorativas y problemas legislativos), op. cit., p. 1464.

25 El MCR tiene una tendencia omnicomprensiva, por cuanto se refiere a todo el Derecho contractual privado. E. Valpuesta GASTAminza, “El ámbito de regulación del futuro 'derecho contractual europeo'. De los principios sobre contratos comerciales a un derecho contractual general que incluya relaciones con consumidores", en E., Bosch Capdevila (dir.), Decanato del Colegio de Registradores de Cataluña (coord.), op. cit., p. 407.

26 Para Gómez Gállico tres son los objetivos del MCR: “a) Elaborar los principios fundamentales del Derecho privado europeo. b) Dar definiciones de ciertos términos legales claves. c) Establecer reglas de derecho contractual que sirvan de modelo, tanto reglas generales como reglas específicas para determinados contratos". J. Gómez Gállico, "La repercusión en derecho español de las propuestas de armonización del Derecho Contractual Europeo”, en E. Bosch Capdevila (dir.), Decanato del Colegio de Registradores de Cataluña (coord.), Derecho contractual europeo. Problemática, propuestas y perspectivas, op. cit., pp. 526-527.

27 V. De Priego Fernández, "Derecho contractual europeo y evicción: la superación del régimen de saneamiento", en Ma . del C. Gómez Laplaza (coord.), Cuestiones sobre la compraventa en el Código civil. Principios europeos y Draft, Colección Monografias de Derecho civil, II. Obligaciones, Madrid, Dykinson, 2012, p. 228.

28 En este sentido, De la Cuesta Rute señala que: "El contenido del DCFR es expresivo de la ambición que subyace a su concepción, que parece muy próxima a la de sentar las bases no ya solo de un derecho contractual europeo, subrayando el propósito unificador de esa parte del derecho privado, sino mucho más todavía de una unificación del derecho general del tráfico patrimonial propio en nuestros días de los países miembros de la Unión Europea". De la Cuesta Rute, "Sobre la unificación del Derecho privado patrimonial en Europa”, op. cit., p. 25.

29 Al respecto, DíAz Romero señala que: "El DCFR es un texto académico en el que se exponen los resultados de un gran proyecto de investigación europeo que invita a la reflexión, promueve el conocimiento del Derecho Privado europeo y muestra un análisis comparativo de los ordenamientos jurídicos europeos que parten de una base común, y pueden aportar soluciones a los problemas y dudas jurídicas que se plantean ante los tribunales europeos y organismos oficiales encargados de armonizar y modernizar los Derechos nacionales y construir un Derecho Privado europeo". Mª . del R. DíAz Romero, "Extensión de la condición resolutoria explícita en la contratación inmobiliaria”, en L. Díez-Picazo, Ponce de León, Revista Crítica de Derecho Inmobiliario (721) (2010), p. 2285.

30 S. SÁnchez LoRenzo, "La unificación del Derecho contractual y su problemática: la respuesta de la Unión Europea”, en E. Bosch Capdevila (dir.), Decanato del Colegio de Registradores de Cataluña (coord.), op. cit., p. 96.

31 En contra se pronuncia De la Cuesta Rute, quien expresa lo siguiente: "De este modo podemos decir que el DCFR se aparta del Law\&Economics, sin que ello signifique que se olvide de valorar los efectos económicos de los demás principios y de las normas respecto tanto de lo que las partes de la relación obligatoria persiguen como de lo que concierne al interés público. Por ello, sin duda, el borrador o proyecto se hace objeto de crítica por los partidarios del análisis económico del derecho". De la Cuesta Rute, "Sobre la unificación del Derecho privado patrimonial en Europa”, op. cit., p. 32. Al respecto, véase también Valpuesta Gastaminza, "La propuesta de Derecho privado unificado de obligaciones y contratos para Europa: el Draft Common Frame of Reference", op. cit., pp. 79-80.

32 Aunque para De la Cuesta Rute lo que se patrocina es el "Estado de bienestar", en efecto, señala este autor que: "No deja de ser curiosa esta preocupación por la vinculación con los derechos 
el MCR, a diferencia de los PECL, ${ }^{33}$ limita el accionar de la buena fe, además, su ámbito de aplicación se restringe a los contratos de consumo. Asimismo, se limita la revisión de las cláusulas abusivas. ${ }^{34} \mathrm{El} \mathrm{MCR}$, según la doctrina española, no constituye un trabajo que haya logrado superar las objeciones y los defectos de los PECL, pues, no solo plantea soluciones ambiguas y vagas, ${ }^{35}$ sino que, además, por ser únicamente un "marco de referencia", cuya finalidad es orientar la solución jurisprudencial, ${ }^{36}$ pero que en ningún caso resulta obligatorio para el juez. ${ }^{37}$ Con todo, pienso que constituye un notable esfuerzo por sentar las bases para una futura regulación en materia de contratos en Europa. ${ }^{38}$ Además, los fines que se propuso eran inicialmente modestos, dado que es un marco referencial de carácter facultativo (soft law), ${ }^{39}$ en el cual los legisladores se pudieran inspirar ${ }^{40}$

humanos una vez que precisamente se achaca al proyecto dejar al margen el objetivo político de promover las metas que deben proponerse como comunes que han de ser para los ciudadanos europeos. De todas maneras, en esta cuestión van implícitos dos aspectos por completo diferentes, que no obstante tienden a confundirse por los patrocinadores del 'Estado de Bienestar'". DE LA Cuesta Rute, "Sobre la unificación del Derecho privado patrimonial en Europa”, op. cit., p. 34.

33 La buena fe se encuentra consagrada en los PECL como una regla de interpretación [art. 1:106 (1)] y como una regla de conducta [art. 1:102 (1)]. M. E. STORME, "Good faith and contents of contracts in European private law”, en S. Espiau Espiau, A. Vaguer Aloy (eds.), Bases de un Derecho contractual europeo, Valencia, Tirant lo Blanch, 2003, p. 22. M. CHAmorro PosAdA, "Diligencia y responsabilidad contractuales por error en el abono en cuenta corriente bancaria (un apunte sobre la buena fe en el derecho contractual europeo)", en S. Espiau Espiau A. Vaguer Aloy (eds.), Bases de un Derecho contractual europeo, op. cit., pp. 31-39.

34 I. González Pacanowska, "Los principios lando", en E. Bosch Capdevila (dir.), Decanato del Colegio de Registradores de Cataluña (coord.) Derecho contractual europeo. Problemática, propuestas y perspectivas, op. cit., p. 170.

35 En este sentido, CAstilla Barea señala que: "Entiendo que el resultado, [la incorporación de los DRAFT en el sistema jurídico español] por tanto, no mejoraría demasiado la actual situación de dispersión normativa y los problemas que ella suscita". M. CASTILLA BAREa, "La unificación de los diversos regimenes de saneamiento, poros y vicios ocultos y falta de conformidad de los bienes vendidos: ¿una cuestión pendiente en materia de compraventa?”, en $\mathrm{M}^{\mathrm{a}}$. del C. Gómez LAPLAZA (coord.), Cuestiones sobre la compraventa en el Código civil. Principios europeos y Draft, op. cit., p. 95.

36 En este sentido, Schulze señala que: "El MCR persigue la finalidad de crear una nueva sistemática del Derecho de contratos y, además, una Parte general para el Derecho contractual comunitario”. R. Schulze, "El Acquis Communautaire y el Marco Común de Referencia para el Derecho contractual europeo", en Ma . P. Ferrer Vanrell, A. Anselmo Cañellas (dirs.), Principios de Derecho contractual europeo y Principios de Unidroit sobre contratos comerciales internacionales, Actas del Congreso Internacional celebrado en Palma de Mallorca, 26 y 27 de abril de 2007, Madrid, Dykinson, 2009, p. 58.

37 G. García Cantero, "La traducción española de la parte general del Código europeo de contratos", en Ante la unificación europea del Derecho contractual: Incidencia en España del Anteproyecto del Grupo de Pavia, s/f, p. 45, en http://www.unizar.es, fecha de consulta: 17 de octubre de 2014.

38 Aun cuando algunos autores han alabado el MCR. En este sentido, ARRoYo I AmAYuELAs expresa lo siguiente: "[La publicación del MCR] evidencia la rápida evolución que ha experimentado el Derecho privado europeo". ARroyo i AmaYuelas, "Hacia un derecho contractual más coherente: la sistematización del acervo contractual comunitario", op. cit., p. 209. S. CÁmARA LAPUEnTE, "Una aproximación al arrendamiento de bienes muebles (lease of goods) en el Marco Común de Referencia”, en E. Bosch Capdevila (dir.), Decanato del Colegio de Registradores de Cataluña (coord.), Derecho contractual europeo. Problemática, propuestas y perspectivas, Barcelona, Bosch, 2009, p. 268; VAguer Aloy, "El Marco Común de Referencia”, op. cit., pp. 261-262.

39 Recordemos que lo mismo se aplica para los PECL. Gómez GÁllico, "La repercusión en derecho español de las propuestas de armonización del Derecho Contractual Europeo”, op. cit., p. 528.

40 En este sentido, Medina Ortega señala que: "Para un sector de la doctrina [el profesor de la Universidad de Panteón-Sorbona de París, Pierre Legrand], el intento de armonizar el Derecho privado de la Unión Europea a través de la codificación no solo está condenado al fracaso de antemano sino que, además, es intrínsecamente negativo desde el punto jurídico, económico, social y político". Medina ORtega, "El Derecho patrimonial europeo en la perspectiva del Programa de Estocolmo", op. cit., p. 87. 
y ser usado como ratio scrita o ius commune. ${ }^{41}$ Este instrumento estaba listo en $2007,{ }^{42}$ y su redacción estuvo a cargo de un grupo de juristas que se reunieron en dos secciones: ${ }^{43}$ el "Study Group on a European Civil Code" ("Study Group"), ${ }^{44}$ y el "Research Group on EC Private Law" (“Acquis Group”). ${ }^{45}$ El primer grupo se creó en 1999, con la finalidad de elaborar un conjunto de reglas y principios que reemplazó a la Comisión Lando. ${ }^{46} \mathrm{El}$ segundo grupo fue creado con el propósito de crear nuevas reglas y perfeccionar las ya existentes, es decir, su objetivo no es crear soluciones específicas para casos concretos, sino elaborar unos verdaderos restatements a nivel europeo. ${ }^{47} \mathrm{El}$ primero se organizó en varios subgrupos de trabajo a cargo de un teamleader. ${ }^{48}$ Por su parte, con el Acquis Grupo se pretende elaborar una serie de principios jurídicos de carácter general en materia de contratos, a partir de la regulación que, sobre el particular, ofrecen los diversos sistemas jurídicos, como asimismo, las sentencias del Tribunal de Justicia Europeo. ${ }^{49}$ Lo anterior debido a que el derecho comunitario está constituido, principalmente, por directivas que versan sobre materias precisas y que no presentan una debida sistematización y armonía entre ellas. El Acquis communautaire ${ }^{50}$ se refiere a la

41 Sánchez LoRenzo, "La unificación del Derecho contractual y su problemática: La respuesta de la Unión Europea”, op. cit., pp. 96 y 100.

42 En este sentido, SÁnchez LoRenzo señala que: "El Proyecto de MCR de 29 de diciembre de 2007 desveló, empero, una cierta germanización del nuevo, desplazado desde el contrato a las obligaciones, que ha justificado las críticas del propio O. LANDo [se suponía que los PrinciPIOs LANDo serían su fuente principal]". Idem, p. 97.

$43 \mathrm{Al}$ respecto, véase Eidenmüller, Faust, Grigoleit, Jansen, Wagner, Zimmermann, El marco común de referencia para el Derecho privado europeo. (Cuestiones valorativas y problemas legislativos), op. cit., pp. 1470 y ss.

44 En este sentido, De Priego Fernández señala que: "La redacción del CFR fue encargada por la Comisión Europea a una red internacional de juristas en la que destacan dos grupos: el Study Group on a European Civil Code y el Research Group on EC Private Law (Acquis Group)". DE PRIEGO FERnández, "Derecho contractual europeo y evicción: la superación del régimen de saneamiento", op. cit., p. 227.

45 Schulze, "El Acquis Communautaire y el Marco Común de Referencia para el Derecho contractual europeo", op. cit., p. 51. Este grupo, cuyo nombre completo es "Research Group on EC Private Law", fue creado "Ip]ara el estudio y mejora del Derecho comunitario ya existente en materia contractual”. VAlpuesta GastaminZA, "El ámbito de regulación del futuro 'derecho contractual europeo'. De los principios sobre contratos comerciales a un derecho contractual general que incluya relaciones con consumidores", op. cit., p. 66.

46 En este sentido, VAlpuesta Gastaminza señala que: "El DCFR no es una simple suma o yuxtaposición de los Acquis Principles (teoría general del contrato) y los Principles of European Law (parte especial de contratos), sino una nueva exposición de la teoría general y una nueva redacción de los PECL”. Idem, p. 68.

$47 \quad$ Idem, pp. 66 y 67.

48 En este sentido, Vaguer Aloy señala que: "Si uno dibuja el mapa de los distintos equipos, descubre que su sede está en Holanda (dos grupos, uno con tres subgrupos), Alemania (tres grupos), Francia (un grupo), Austria (un grupo) y Noruega (un grupo), lo que demuestra, aparentemente, un poco peso de los países latinos o de la Gran Bretaña". Vaguer Aloy, "El Marco Común de Referencia”, op. cit., p. 246.

49 Al respecto, VAgUer Aloy señala que: “Ambos grupos, el Study Group y el Acquis, han desarrollado sus actividades en paralelo y con plena autonomía. Sin embargo, conjuntamente debían dar forma al draft del CFR. Idem, p. 249.

50 Sobre esto, SÁnchez LoREnzo expresa lo siguiente: "los denominados Acquis Principles han supuesto una verdadera mejora, muy sustancial, del Derecho comunitario vigente, especialmente en materia de contratos celebrados por consumidores (estrategia B2C)". SÁnchez Lorenzo, "La unificación del Derecho contractual y su problemática: la respuesta de la Unión Europea”, op. cit., p. 101. Al respecto, Schulze señala que: "Hay que partir de la tesis de que el Derecho comunitario ya existente, el llamado 'acquis communautaire, permite desarrollar principios y estructuras generales que 
esencia del derecho contractual, partiendo desde los tratos preliminares, hasta los remedios en caso de incumplimiento. ${ }^{51}$ Este grupo se ha centrado en la presentación de un marco coherente de normas jurídicas que generalicen su aplicación a campos para los que antes no estaban destinadas y, sobre todo, en el establecimiento de principios que se erijan como el cimiento de la futura expedición de leyes comunitarias o nacionales, pudiendo ser tenido como un restatement de principios, reglas y normas, ${ }^{52}$ sobre la base de los principios de la libertad, seguridad jurídica, justicia y eficiencia. ${ }^{53} \mathrm{El} \mathrm{MCR}$ académico fue considerado por la Comisión de Justicia del Comité de Asuntos Legales del Parlamento Europeo como un verdadero "embrión" de Código Civil europeo, en la reunión celebrada el 12 de enero de 2010. ${ }^{54} \mathrm{El} 26$ de abril de 2010, la Comisión decretó una Decisión mediante la cual se creaba un Grupo de expertos cuya finalidad era la elaboración de un MCR, en materia de derecho contractual europeo. ${ }^{55}$ Por otra parte, se dice que el principal problema que la doctrina achaca al MCR es que el buen funcionamiento del mercado europeo no solo depende de la existencia de un conjunto de principios sino que, además, necesita de normas sustantivas y procesales ${ }^{56}$ que lo ordenen. ${ }^{57}$ Aun cuando en realidad, así lo piensa Sánchez Lorenzo, esta se podría considerar como una ventaja, ${ }^{58}$ llegando a calificarlo de "embrión de Código Civil europeo”. ${ }^{59}$ En este mismo sentido se pronuncia Rodríguez Marín. ${ }^{60}$

deben ser utilizadas tanto por una doctrina común, como por la jurisprudencia europea”. SchulzE, "El Acquis Communautaire y el Marco Común de Referencia para el Derecho contractual europeo", op. cit., p. 634 .

51 Idem, p. 61.

52 Arroyo i Amayuelas, "Hacia un derecho contractual más coherente: la sistematización del acervo contractual comunitario”, op. cit., pp. 210-211.

53 De la Cuesta Rute, "Sobre la unificación del Derecho privado patrimonial en Europa”, op. cit., p. 35.

54 En este sentido, y para evitar críticas en cuanto a que constituye un texto puramente académico ('stakeholder-meetings'), se ha pretendido realizar una completa revisión de dichos principios, para así aplacar a la opinión pública. Eidenmüller, Faust, Grigoleit, Jansen, Wagner y Zimmermann, El marco común de referencia para el Derecho privado europeo. (Cuestiones valorativas y problemas legislativos), op. cit., pp. 1470-1471. Redondo Trigo, "De los Principios Lando al Marco Común de Referencia del Derecho Privado Europeo. Hacia un nuevo ius commune”, op. cit., p. 1668.

55 Valpuesta Gastaminza, "El ámbito de regulación del futuro 'derecho contractual europeo'. De los principios sobre contratos comerciales a un derecho contractual general que incluya relaciones con consumidores", op. cit., p. 84.

56 Así lo reconoce Sánchez LoREnzo, quien expresa que: "En suma, resulta poco concebible que los Principios Unidroit, los PECL o el MCR puedan eliminar de forma definitiva la necesidad de dotar al contrato de un Derecho nacional o estatal de referencia". SÁnchez LorEnzo, "La unificación del Derecho contractual y su problemática: la respuesta de la Unión Europea”, op. cit., p. 104.

57 De Priego Fernández, "Derecho contractual europeo y evicción: la superación del régimen de saneamiento", op. cit., p. 227.

58 En este sentido, SÁnchez Lorenzo expresa lo siguiente: "Ciertamente, los Acquis Principles cumplen una misión esencial desde este punto de vista, pero más allá de su valor práctico y didáctico, se orientan hacia la necesaria gestación de un genuino Derecho contractual europeo". SÁNCHEZ LORENzo, "La unificación del Derecho contractual y su problemática: la respuesta de la Unión Europea", op. cit., p. 86.

59 Idem, p. 87.

60 Rodríguez Marín expresa lo siguiente: "El Marco Común de Referencia, con fecha 2009 (DCFR), elaborado con la prestación de ser una de las claves para la unificación europea del Derecho privado, así como fuente de inspiración para la enseñanza del Derecho en Europa y por supuesto para el legislador, ya que aborda de forma integral el régimen jurídico del cumplimiento". C. RodRíGuez MARín, "La Propuesta de Anteproyecto de Modernización del Código Civil en materia de obligaciones y contratos. Diferencias y similitudes con el cumplimiento", en ConseJo GENERAL del Notariado (ed.), Revista Jurídica del Notariado (76) (2010), pp. 271-300. 
Además de lo anterior, la doctrina ha destacado la ambigüedad y vaguedad de las comunicaciones de 2001, 2002 y 2004 sobre el objetivo que inspiraba a los grupos de trabajo, lo que se expresa también en el MCR. ${ }^{61}$ Por último, la tensión existente entre el common law y el civil law se manifiesta nuevamente en el MCR. ${ }^{62}$ En este sentido, se ha dicho que no existe una preeminencia de la autonomía de la voluntad por sobre los otros principios inspiradores del MCR, sino que existe una clara intención de equiparar, en importancia, a la autonomía privada con los otros principios. Ello se ha logrado limitando la autonomía de la voluntad a través de una serie de reservas de carácter objetivo. Para la doctrina, dichas limitaciones van incluso más allá de lo que se llama la "sustanciación de la autonomía privada”. La reducción del ámbito de competencia de la autonomía privada cede en beneficio de la buena fe y los usos mercantiles, que se constituyen así como la esencia del derecho contractual (el artículo II.-1:102 [1]) somete a la autonomía de la voluntad a la buena fe. ${ }^{63}$

En cuanto a la estructura, ${ }^{64}$ es posible decir que el MCR se divide en diez libros y contiene, además, dos apéndices. ${ }^{65}$ Los libros se organizan de la siguiente forma: ${ }^{66}$ i) el Libro I trata de las disposiciones generales; ii) el Libro II se refiere a los contratos y actos jurídicos; iii) el Libro III versa sobre las obligaciones y derechos correspondientes; iv) el Libro IV contempla normas sobre los contratos en especial; v) el Libro V trata la agencia oficiosa o intervención benevolente; vi) el Libro VI sobre la responsabilidad extracontractual; vii) el Libro VII se refiere al enriquecimiento sin causa, viii) el Libro VIII trata la adquisición y pérdida del dominio de bienes muebles (goods), ix) el Libro IX se refiere a las garantias reales en bienes muebles $\mathrm{y}$, por último, $\mathrm{x}$ ) el Libro $\mathrm{X}$ versa sobre los trust. ${ }^{67}$

61 De la Cuesta Rute, "Sobre la unificación del Derecho privado patrimonial en Europa”, op. cit., pp. 25-26.

62 En este sentido, De la Cuesta Rute señala que: "Un punto que no puede dejar de mencionarse es el de las críticas que se dirigen al DCFR por su invasión de aspectos del derecho de contratos cuyas normas internas de los Estados responden a tradiciones jurídicas tan diferentes como la propia del derecho anglosajón y la de derecho continental, por no entrar a señalar las diferencias innegables que se advierten igualmente entre los ordenamientos de los Estados miembros del continente europeo también en puntos especialmente relevantes”. Idem, p. 39.

63 Eidenmüller, Faust, Grigoleit, Jansen, Wagner,Zimmermann, El marco común de referencia para el Derecho privado europeo, op. cit., pp. 1485-1487.

64 Idem, pp. 1466 y ss.

65 En este sentido, Eidenmüller, et al. señalan que: "En medio de esta sistemática más bien tradicional, se inserta el ius novum proveniente del acquis communautaire (a veces, ampliamente mediante normas generalizadoras): no discriminación, deberes de información, entrega de bienes o prestación de servicios no solicitados, derechos de desistimiento (todo ello en el libro II), las reglas sobre garantías de bienes de consumo y una pluralidad de normas adicionales protectoras del consumidor en la compraventa (libro IV A)”. Idem, p. 1468.

66 En este sentido, véase M. J. Bonell y R. Pelegi, "Unidroit Principles of International Commercial Contracts and Draft Common Frame of Reference: a Synoptical Table”, en W. Rodin (dir.), Uniform Law Review, NS 14 (2009-3), Milano, Unidroit, 2011, pp. 438 y ss.

67 Valpuesta Gastaminza, “El ámbito de regulación del futuro 'derecho contractual europeo'. De los principios sobre contratos comerciales a un derecho contractual general que incluya relaciones con consumidores", op. cit., pp. 69-72. 


\section{REGULACIÓN DEL DERECHO DE OPCIÓN DEL ACREEDOR EN EL MARCO COMÚN DE REFERENCIA (THE DRAFT COMMON FRAME OF REFERENCE)}

Lo primero que llama la atención de la lectura rápida del MCR, es que la expresión "remedio" aparece mencionada en varias de sus partes, v. gr., en el artículo II. -9:302, a propósito de la estipulación a favor de un tercero ${ }^{68}$ y en el epígrafe del Capítulo IV del Libro IV que se refiere a los "Contratos específicos y derechos y obligaciones que de ellos se derivan". ${ }^{69}$

El Libro III del MCR, como se dijo, se refiere a las obligaciones y sus correspondientes derechos (Obligations and corresponding rights). De este libro nos interesan, particularmente, los tres primeros capítulos. El Capítulo I se refiere a las disposiciones generales en torno al derecho obligacional, fijando el concepto de ciertas nociones jurídicas: obligación, cumplimiento e incumplimiento, buena fe, no discriminación, entre otros; el Capitulo II, por su parte, versa sobre el pago, el cumplimiento por parte de un tercero, la imputación al pago, etc.; el Capítulo III consagra diversos remedios frente al incumplimiento contractual. ${ }^{70}$

El Capítulo I se refiere a conceptos y principios de carácter general en materia de obligaciones creadas por el contrato u otro acto jurídico, la ley, la resolución judicial, o por los usos y las prácticas jurídicamente obligatorias, y sobre la base del principio de la obligatoriedad de los contratos. Este principio les impone a los contratantes el cumplimiento estricto de sus obligaciones. Bajo el concepto de non performance se agrupan el incumplimiento total y absoluto, el retraso en el cumplimiento de la obligación y el cumplimiento defectuoso. ${ }^{71}$

Frente al incumplimiento contractual, ${ }^{72}$ el MCR consagra un conjunto de reme$\operatorname{dios}^{73}$ (o medios de defensa de que dispone el acreedor) ${ }^{74}$ que pueden ser ejercidos

68 A. Jiménez Costa, "Libro II. Capítulos 1 y 2", en A. Vaguer Aloy, E. Bosch Capdevila, Ma. Sánchez GonZÁlez (coords.), Derecho europeo de contratos. Libros II y IV del Marco Común de Referencia, t. I, Barcelona, Atelier Libros Jurídicos, 2012, p. 632.

69 Idem, p. 889.

70 Valpuesta Gastaminza, “El ámbito de regulación del futuro 'derecho contractual europeo'. De los principios sobre contratos comerciales a un derecho contractual general que incluya relaciones con consumidores", op. cit., pp. 69-72.

71 J. Nanclares Valle, "Libro III. Obligaciones y derechos", en E., Valpuesta Gastaminza (coord.), Unificación del Derecho patrimonial europeo. Marco Común de Referencia y Derecho español, op. cit., pp. 163-164.

72 En este sentido, NANCLARES VAlLE señala que: "El concepto de incumplimiento que se utiliza en el DCFR abarca todo tipo de realización de la prestación debida, dando cabida tanto a los supuestos de incumplimiento total como a los de cumplimiento defectuoso o tardío. Tienen también cabida en dicha categoría tanto los casos de incumplimiento justificado como los de incumplimiento al margen de todo impedimento". Idem, p. 177.

73 En este sentido, Gómez CALLE señala que: "el DCFR explicita que el incumplimiento no queda descartado porque sea excusable (concepto neutro) y menciona expresamente el retraso como un supuesto concreto de incumplimiento; probablemente se habría podido prescindir de esa mención, pues, como resulta del propio artículo, no se trata sino de un caso más ('otro') de cumplimiento no acorde con los términos de la obligación". E. Gómez CALLe, "Los remedios ante el incumplimiento del contrato: análisis de la Propuesta de Modernización del Código Civil en materia de obligaciones y

278 contratos y comparación con el Borrador del Marco Común de Referencia”, en MinisteRIO DE JusticIA (Centro de Publicaciones) y Boletín Oficial del Estado (ed.), Anuario de Derecho civil, t. LXV, fasc. I, enero-marzo, Madrid, Librería del Boletín Oficial del Estado, 2012, p. 39.

74 Nanclares Valle, "Libro III. Obligaciones y derechos”, op. cit., p. 177. 
conjuntamente, salvo que tengan el carácter de incompatibles. ${ }^{75}$ Cabe señalar que la indemnización de daños y perjuicios escapa a esta regla, pues, siempre es posible acumularla a otro remedio contractual. Así, v. gr., en el MCR el comprador, en caso de incumplimiento por parte del vendedor, tiene la facultad para solicitar: i) la resolución del contrato (salvo que se trate de un incumplimiento de menor importancia), ${ }^{76}$ ii) el cumplimiento forzado de la obligación, iii) la paralización del cumplimiento del contrato, iv) la reducción del precio y v) la indemnización de perjuicios. ${ }^{77}$ Asimismo, los contratantes, en virtud del principio de la autonomía de la voluntad, pueden excluir o restringir cualquier remedio, siempre que dicha exclusión o restricción no vaya en contra del principio de la buena fe. ${ }^{78}$

La activación de dichos remedios depende, en todo caso, de las circunstancias particulares de cada caso, y se ven limitados cuando el incumplimiento se encuentre justificado ${ }^{79}$ pues, en ese caso, no se podrá imponer el cumplimiento in natura ni tampoco la indemnización de daños y perjuicios. ${ }^{80}$

\subsection{La resolución del contrato por incumplimiento}

El DCFR, a propósito del incumplimiento resolutorio, dispone en la Section 5: Termination, Sub-section 1: Grounds for termination, artículo III.-3:502: Termination for fundamental non-performance, lo siguiente:

(1) A creditor may terminate if the debtor's non-performance of a contractual obligation is fundamental. (2) A non-performance of a contractual obligation is funda-

75 En este sentido, De la Cuesta Rute señala que: "El DCFR sistematiza de manera estimable los remedios con que cuenta el acreedor insatisfecho ante el incumplimiento de la otra parte. No todos los remedios están disponibles para ser utilizados en todos los casos, porque dependerá de si el incumplimiento es o no imputable al deudor y de si el cumplimiento es o no todavía posible". DE la Cuesta Rute, "Sobre la unificación del Derecho privado patrimonial en Europa”, op. cit., p. 52. Nanclares Valle, "Libro III. Obligaciones y derechos”, op. cit., p. 178.

76 En este sentido, Nanclares VALLE expresa lo siguiente: "El incumplimiento de la obligación permite al acreedor comunicar este extremo al deudor, comunicación que será eficaz si se realiza correctamente, con independencia de que no llegue, llegue con retraso o de manera inexacta a conocimiento del deudor, desplegando sus efectos no desde la fecha en que fue emitida y tampoco desde la fecha en que fue recibida y conocida por el destinatario (como sucedería si aplicásemos el precepto que regula con carácter general las notificaciones en el DCFR: art. I.-1:1009, respecto del cual el art. III.-3:106 supone una excepción) sino desde la fecha en que, en circunstancias normales, debería haber sido conocida por el deudor". Ibid.

77 De Priego Fernández, "Derecho contractual europeo y evicción: la superación del régimen de saneamiento", op. cit., p. 232; Gómez Calle, "Los remedios ante el incumplimiento del contrato: análisis de la Propuesta de Modernización del Código Civil en materia de obligaciones y contratos y comparación con el Borrador del Marco Común de Referencia”, op. cit., pp. 44 y ss.

78 Nanclares Valle, "Libro III. Obligaciones y derechos", op. cit., p. 178.

79 En este sentido, NANClares VAlle señala que: "El incumplimiento será excusable si se debe a un impedimento ajeno al control del deudor y si no se podía esperar razonablemente que lo evitase o superase (supuestos de fuerza mayor). Asimismo, tratándose de obligaciones contractuales o nacidas de un acto jurídico, será excusable el impedimento que sea imprevisible para el deudor en el momento de contraer la obligación, no así el que debió ser tenido en cuenta. Siendo temporal el impedimento, la excusa durará el mismo tiempo que dure aquél, a menos que el retraso constituya per se un incumplimiento fundamental (como sucedería en obligaciones sometidas a término Idem, p. 177. 
mental if: (a) it substantially deprives the creditor of what the creditor was entitled to expect under the contract, as applied to the whole or relevant part of the performance, unless at the time of conclusion of the contract the debtor did not foresee and could not reasonably be expected to have foreseen that result; or (b) it is intentional or reckless and gives the creditor reason to believe that the debtor's future performance cannot be relied on..$^{81}$

En este sentido, se señala que la primera causal de resolución contractual es el "incumplimiento fundamental" de alguna de las obligaciones emergentes de un contrato bilateral. Este, como es sabido, equivale al incumplimiento esencial que priva al acreedor de aquellas cosas que tenía expectativas de recibir, salvo que el deudor no hubiere previsto o debido prever, o es imprudente y le permite al acreedor no creer que no podrá en el futuro recibir lo que espera le sea entregado. ${ }^{82}$

Frente a un incumplimiento no fundamental, se discute si el retraso en el cumplimiento de la obligación puede llegar a ser causa de resolución, pues el acreedor está facultado para notificarle al deudor la concesión de un plazo adicional y razonable para que cumpla su deber. Es posible establecer que la resolución procederá automáticamente y sin necesidad de nueva notificación, en caso de que el deudor no cumpla con su obligación dentro del nuevo plazo. ${ }^{83}$

La resolución extingue las obligaciones bilaterales pendientes, por ello, las partes quedan liberadas de su deber. En los contractos de tracto sucesivo, la resolución solo afecta a las prestaciones futuras. Una vez resuelto el contrato, procederán las restituciones mutuas, debiéndose devolver los bienes que se hubieran entregado en virtud del negocio, incluidos los frutos. Los bienes y sus frutos no se deben devolver cuando dicha restitución suponga un coste o esfuerzo excesivo para el contratante que debe devolverlos. En este último caso, se repetirá el valor de las cosas que debian ser restituidas. ${ }^{84}$ En este sentido, se ha dicho que la conformidad de la cosa equivale a la conformidad con el negocio. Lo anterior por cuanto la obligación de dar impone al deudor el deber de dar una cosa que sea conforme al contrato. Cuando se habla de "cosa", al igual que lo hace el Diccionario de la $\mathrm{RAE},{ }^{85}$ el MCR entiende este concepto en sentido amplio, referido tanto a bienes corporales como inmateriales, muebles o inmuebles. Así, el artículo IV.-A. 1:101 MCR se refiere a la propiedad intelectual. ${ }^{86}$

81 R. García PÉrez, "El incumplimiento anticipado o previsible (anticipated non performance) como incumplimiento resolutorio en la Propuesta de Modernización del Código civil”, en R. Bercovitz Rodríguez-Cano y E. Rubio Torrano, BIB 2012\3025, Revista Doctrinal Aranzadi Civil-Mercantil (7) (2012), p. 22, en http://www.westlaw.es/, fecha de consulta: 2 de enero de 2014.

82 NAnclares Valle, “Libro III. Obligaciones y derechos”, op. cit., p. 183.

83 Idem, pp. 183-184.

84 Idem, pp. 185-186.

85 Real Academia Española, Diccionario de la Lengua Española, t. I, 22 edición, México, Espasa Calpe, 2001 , p. 671.

$280 \quad 86 \quad M^{a}$. R. LLÁCER MataCÁs, "La garantía por falta de conformidad y el cumplimiento 'no conforme’: el derecho español a la luz del Marco Común de Referencia”, en E. Bosch Capdevila (dir.), Decanato del Colegio de Registradores de Cataluña (coord.), Derecho contractual europeo. Problemática, propuestas y perspectivas, op. cit., p. 469. 
En cuanto al ejercicio de la facultad resolutoria, el MCR permite que se realice por medio de una declaración del acreedor, sin perjuicio de que el juez pueda revisar con posterioridad si concurren los requisitos de la resolución contractual. ${ }^{87} \mathrm{El}$ acreedor debe proceder a resolver el contrato dentro de un plazo razonable, que se contabiliza desde que expira el plazo adicional que tiene el deudor para cumplir o asegurar el cumplimiento de la obligación. ${ }^{88}$

\subsection{El cumplimiento forzado de la obligación}

En el caso de las obligaciones pecuniarias, el acreedor no solo tiene la facultad para cobrarle la cantidad debida al deudor, sino, además, el cumplimiento de sus obligaciones bilaterales y propias, aun cuando el deudor no tenga la disposición de recibir las cosas que el otro contratante debe entregarle, salvo cuando el acreedor haya realizado, razonablemente, un negocio sustituto, que no le suponga al deudor un excesivo coste, o cuando el cumplimiento no parezca ser razonable conforme a las circunstancias particulares del caso. Ahora bien, tratándose de las obligaciones no pecuniarias, el acreedor tiene la opción para exigirle al deudor el cumplimiento de la obligación o el cumplimiento por equivalencia (para exigir una suma de dinero que reemplace al objeto de la prestación incumplida).

Por otra parte, existen ciertas excepciones al cumplimiento específico (in natura), tal es el caso de las prestaciones ilícitas o cuando su cumplimiento fuese imposible (física o jurídicamente), cuando su exigencia resultare excesivamente costosa (a este supuesto se le llama "imposibilidad económica"), o fuera una obligación intuito personæ, salvo que pueda delegarse en terceros. Asimismo, constituye una excepción al cumplimiento específico, justificada por el principio de la buena fe, el hecho de que el acreedor no exija la obligación dentro de un plazo razonable, contado desde la fecha en que supo y pudo razonablemente enterarse del incumplimiento. En este caso, tampoco podrá el acreedor exigir una indemnización de perjuicios. ${ }^{89}$

En cuanto al llamado "incumplimiento anticipado" ("anticipatory nonperformance"), ${ }^{90}$ el MCR sustituye la frase "anticipatory non-performance" por la expresión "anticipated no performancees", que es más precisa, pues la norma no regula el incumplimiento futuro real, sino que se refiere a una situación hipotética: el supuesto incumplimiento que justificaría la resolución contractual y sería más

87 Gómez Calle, "Los remedios ante el incumplimiento del contrato: análisis de la Propuesta de Modernización del Código civil en materia de obligaciones y contratos y comparación con el Borrador del Marco Común de Referencia”, op. cit., pp. 70-71.

88 Idem, p. 73

89 Nanclares Valle, “Libro III. Obligaciones y derechos”, op. cit., pp. 181-182.

90 En este sentido, Miláns del Bosch Portolés señala que: “[Esta institución] permite la resolución del contrato no ya por el juez sino por las partes, antes de que la otra parte hubiere comenzado a cumplir sus obligaciones y fuere patente que incurrirá en incumplimiento”. MiLÁns DEL Bosch PORTOLÉs, "Cumplimiento e incumplimiento del contrato internacional", op. cit., p. 691. 
eficiente para el acreedor, porque lo autoriza a dejar sin efecto el negocio, incluso antes de que se produzca el incumplimiento de la contraparte. ${ }^{91}$

\subsection{La paralización del cumplimiento del contrato}

En este sentido, el artículo III.-3:401, apartados 2 y 3, de los DCFR faculta al acreedor para "suspender" el cumplimiento de su obligación, aun cuando deba cumplir antes que su deudor, cuando crea razonablemente que la parte contraria incumplirá con su deber, siempre que comunique al deudor dentro de un plazo razonable. Este aviso o notificación emplaza al deudor para que destruya la "razonabilidad" en la petición del acreedor, o bien, proceda a enervar la resolución anticipada, siempre que garantice su cumplimiento. ${ }^{92}$ La notificación no invalida la resolución, pero supone que el acreedor se hará cargo de los daños y perjuicios causados al deudor. ${ }^{93} \mathrm{El} \mathrm{MCR} \mathrm{posibilita} \mathrm{que} \mathrm{se} \mathrm{suspenda} \mathrm{o} \mathrm{paralice} \mathrm{la} \mathrm{ejecución} \mathrm{de}$ la obligación, total o parcialmente, por quien deba cumplir la obligación al mismo tiempo o después que su contraparte, o por quien debe cumplir su obligación en primer lugar. ${ }^{94}$ En virtud de la anterior norma se consagra la exceptio inadimpleti contractus (exceptio non rite adimpleti contractus), según la cual, si el negocio es bilateral, se autoriza a una de las partes a incumplir su obligación cuando la contraparte, debiendo cumplir coetáneamente o con posterioridad, razonablemente crea que esta parte incumplirá su obligación. Esta razonabilidad debe estar conforme a la buena fe. ${ }^{95}$

\subsection{La reducción del precio}

Cuando la cosa entregada por el deudor no está conforme con lo que reza el contrato, se faculta al acreedor para exigir una reducción en el precio, en proporción a la disminución en el valor de la cosa entregada. Es claro que este remedio es la versión moderna de la actio quanti minoris, establecida en el artículo 1486 del CC español. En este caso, el acreedor carece de acción indemnizatoria para exigir el

91 García Pérez, "El incumplimiento anticipado o previsible (anticipated non performance) como incumplimiento resolutorio en la Propuesta de Modernización del Código civil”, op. cit., p. 11. Al respecto, NANCLARES VAlLE señala que: "La resolución cabe con carácter anticipado respecto de la fecha de vencimiento de la obligación si, tratándose de un incumplimiento fundamental, el deudor declara que no cumplirá la obligación o si de cualquier otra forma queda patente que se producirá dicho incumplimiento. En caso de creer, con razonable fundamento, que se producirá un incumplimiento fundamental de una obligación, puede el acreedor exigir la prestación de garantías adecuadas, de modo que si el deudor no las ofrece en un plazo razonable cabrá la terminación de la relación contractual". NAnclares Valle, "Libro III. Obligaciones y derechos", op. cit., p. 184.

92 En este sentido, Miláns del Bosch Portolés señala que: "En la práctica, el incumplimiento anticipado puede justificarse tanto por el comportamiento de la otra parte, quien por ejemplo hace saber de manera cierta e inequivoca que no cumplirá sus obligaciones, o de circunstancias más objetivas como, por ejemplo, la destrucción de una fábrica por el fuego”. Miláns del Bosch PorTolÉs, “Cumplimiento e incumplimiento del contrato internacional", op. cit., p. 691.

93 García Pérez, "El incumplimiento anticipado o previsible (anticipated non performance) como incumplimiento resolutorio en la Propuesta de Modernización del Código civil”, op. cit., p. 11.

94 Idem, p. 49.

95 Nanclares Valle, "Libro III. Obligaciones y derechos”, op. cit., p. 182. 
resarcimiento de la disminución en el valor de la cosa entregada, pero sí puede solicitar indemnización de daños y perjuicios en virtud de otra causa. ${ }^{96}$

La reducción del precio se consagra en el MCR en el artículo III.-3:601. Supone la existencia de un contrato bilateral, en el cual una de las partes debe pagar una suma de dinero. Lo anterior implica, además, que la contraparte no ejecute completamente la conducta prevista como debida; frente a esa falta de conformidad, ${ }^{97}$ el otro contratante puede solicitar una rebaja en el precio, pudiendo, además, solicitar una indemnización por daños y perjuicios. ${ }^{98}$

\subsection{La indemnización de daños y perjuicios}

Para el derecho moderno, este es el remedio por excelencia. Significa que el acreedor diligente puede, cuando el deudor no ha cumplido su obligación, demandar el resarcimiento de los daños y perjuicios. En la indemnización se incluyen los daños patrimoniales y los morales. El deudor únicamente responde por los daños y perjuicios efectivamente previstos o que pudo haber previsto razonablemente. ${ }^{99}$

En caso de que el acreedor hubiera contribuido al incumplimiento del contrato, el deudor quedará liberado del deber de indemnizar los daños y perjuicios que se hubieren provocado a consecuencia directa del comportamiento del acreedor. Por otra parte, el deudor tampoco responderá de los daños y perjuicios que se hubieren ocasionado debido a que el acreedor no adoptó las medidas necesarias para "mitigar" esos efectos negativos, conforme a la buena fe. Una vez cumplido dicho deber de mitigar, el acreedor tendrá derecho a pedir la devolución de los costes razonables en que hubiere incurrido. Ahora bien, en las obligaciones pecuniarias, el acreedor tiene derecho a exigir los intereses ${ }^{100}$ devengados entre el día del vencimiento del plazo para cumplir hasta el día efectivo del pago. Dichos intereses se

$96 \quad$ Idem, p. 187.

97 En el Derecho civil español, véase I. Herbosa Martínez, A. B. Veiga Copo, E. Cencerrado Millán, "El contrato de compraventa. La compraventa mercantil. El contrato de suministro”, en M. YzQUIERDo Tolsada (dir.), Contratos. Civiles, mercantiles, públicos, laborales e internacionales con sus implicancias tributarias, t. I, Contratos de finalidad traslativa de dominio, Navarra, Thomson Reuters (Legal) Limited, Aranzadi, 2014, pp. 619 y ss.

98 Gómez Calle, "Los remedios ante el incumplimiento del contrato: análisis de la Propuesta de Modernización del Código Civil en materia de obligaciones y contratos y comparación con el Borrador del Marco Común de Referencia”, op. cit., pp. 61-62.

99 Nanclares Valle, "Libro III. Obligaciones y derechos", op. cit., pp. 188-189. En este sentido, NAnclaRES VALLE señala que: "Cabe distinguir entre obligaciones de resultados y obligaciones de medios. En aquellas, la no realización de la prestación debida hubiese actuado con toda la diligencia debida, a menos que existiera un impedimento que permitiera justificar el incumplimiento y eximir de responsabilidad al deudor. Por el contrario, en las obligaciones de medios el deudor será responsable si no obra con la profesionalidad y diligencia precisa, que habrá de establecerse en el contrato y que, de no ser así, se identificará con la culpa”. Idem, p. 188.

100 Con relación a los intereses, NAnclares Valle dice que: "La aplicación de la libertad de pacto al momento a partir del cual se devengan intereses y al tipo de interés mismo, es objeto de restricciones en la medida que esas cláusulas incluidas en los contratos comerciales serán abusivas (por desviarse notoriamente de las buenas prácticas comerciales y operar en contradicción con la buena fe y la corrección en los tratos) si retrasan la fecha de devengo del interés o si reducen el tipo de interés aplicable según el artículo citado en el párrafo precedente. También lo serán si tales cláusulas permiten al deudor pagar el precio de los bienes o servicios suministrados con posterioridad 
establecen conforme al tipo de interés medio aplicado por las instituciones financieras a las grandes cuentas en operaciones de corto plazo. ${ }^{101}$

En esta línea de análisis, conviene examinar el artículo III.-3:710 del MCR, que se refiere al retraso en el cumplimiento de una obligación por parte del empresario, de pagar las mercaderías o los servicios que le fueron prestados, de acuerdo con el grado de conformidad que tuvo y a la fecha en que le fueron entregados o prestados, respectivamente. En el MCR se consagra el anatocismo, de tal forma que los intereses originados se capitalizan cada doce meses. ${ }^{102}$

\section{Conclusiones}

El carácter facultativo (soft law) que presenta el MCR impide que sea aplicado como regla jurídica por los tribunales de justicia. Con todo, su pretensión de constituirse en una referencia (modelo) académica para inspirar a jueces y legisladores, sobre la base de los principios de la libertad contractual, seguridad jurídica y eficiencia, no logra, en mi opinión, superar a los PECL, por cuanto dicha pretensión de universalidad se funda absolutamente en la autonomia de la voluntad, dejando completamente olvidada a la buena fe. Ello se enmarca dentro de principios exclusivamente económicos, que no solo abandonan principios sociales, sino que ven al derecho como un mero instrumento de la economía. Esta tendencia coarta, en mi opinión, el margen de discrecionalidad que tiene el juez. Además, varias de sus normas están redactadas de manera ambigua y vaga.

Sabido es que el mercado común europeo requiere de un marco jurídico estándar para desenvolverse con mayor eficiencia, pero ello no puede suponer la aceptación de nociones económicas extrañas a la tradición continental.

De lo dicho surgen dos preguntas: 1) ¿se debe unificar el derecho europeo de los contratos? y 2) ¿cómo debe hacerse esa europeización? La primera pregunta creo que debería responderse afirmativamente, pues se ha planteado de manera reiterada la conveniencia de unificar el derecho europeo de las obligaciones y los contratos. La segunda, en cambio, resulta más compleja. Leible manifiesta la complejidad que presenta el procedimiento propuesto por la Comisión. Este ha exhortado a la comunidad académica a que trabaje sobre la base de los textos presentados, de manera crítica, con el fin de promulgar en el futuro un Código civil europeo. ${ }^{103}$

al momento en el que los intereses empiezan a devengarse según el art. III-3:710 (2) y (3) DCFR". Idem, pp. 191-192.

101 Idem, p. 191. En este sentido, NANCLARES VALLE señala que: "Cuando el acreedor haya resuelto la relación contractual, la celebración por su parte de un nuevo negocio sustitutivo del anterior, en un plazo razonable y en unas condiciones también razonables, permite a dicho acreedor exigir en vía resarcitoria la diferencia entre el valor de lo que debería haberse cobrado en la relación anterior y lo que debe ser cobrado en función de la nueva relación, además de los daños derivados de cualquier otra pérdida sufrida”. Idem, p. 190.

$284 \quad 102$ Idem, pp. 189-191.

103 S. Leible, "Vías para la unificación del Derecho privado europeo", en Estudios monográficos, trad. de F. Infante Ruiz, en http://www.upo.es, fecha de consulta: 27 de febrero de 2015, p. 1608. 


\section{BIBLIOGRAFÍA}

ArRoyo i Amayuelas, E., "Hacia un derecho contractual más coherente: la sistematización del acervo contractual comunitario", en Bosch Capdevila E., (dir.), Decanato del Colegio de Registradores de Cataluña (coord.), Derecho contractual europeo. Problemática, propuestas y perspectivas, Barcelona, Bosch, 2009, pp. 209-238.

Arroyo I, Amayuelas, E., "Los Principios del Derecho contractual comunitario. Prólogo", en Ministerio de Justicia (Centro de Publicaciones) y Boletín Oficial del Estado (eds.), Anuario de Derecho civil, t. LXI, fasc. I, enero-marzo, Madrid, Libreria del Boletín Oficial del Estado, 2008, pp. 211-239.

Basedow, J., Hopt, K. J., Zimmermann, R., Stier A., et al, The Max Planck Encyclopedia of European Private Law, vols. I y II, Published under the auspices of the Max Planck Encyclopedia of European Private Law, Oxford, Oxford University Press, 2012.

Bonell, M. J., PelEgr R., "Unidroit Principles of International Commercial Contracts and Draft Common Frame of Reference: a Synoptical Table", en W. Rodin (dir.), Uniform Law Review, 14 (2011), pp. 437-554.

CÁmARA LAPUENTE S., "Una aproximación al arrendamiento de bienes muebles (lease of goods) en el Marco Común de Referencia”, en E. Bosch Capdevila (dir.), Decanato del Colegio de Registradores de Cataluña (coord.), Derecho contractual europeo. Problemática, propuestas y perspectivas, Barcelona, Bosch , 2009, pp. 267-310.

Chamorro Posada, M., "Diligencia y responsabilidad contractuales por error en el abono en cuenta corriente bancaria (un apunte sobre la buena fe en el derecho contractual europeo)", en S. Espiau Espiau, A. Vaguer Aloy (eds.), Bases de un Derecho contractual europeo, Valencia, Tirant lo Blanch, 2003, pp. 31-39.

De la Cuesta Rute, J. Ma -., "Sobre la unificación del Derecho privado patrimonial en Europa", en E. Valpuesta GastaminZa (coord.), Unificación del Derecho patrimonial europeo. Marco Común de Referencia y Derecho español, Barcelona, Bosch, 2011, pp. 23-59.

De Priego Fernández, V., "Derecho contractual europeo y evicción: la superación del régimen de saneamiento", en $\mathrm{M}^{\mathrm{a}}$. del C. Gómez LaplazA (coord.), Cuestiones sobre la compraventa en el Código civil. Principios europeos y Draft, Colección Monografias de Derecho civil, II. Obligaciones, Madrid, Dykinson, 2012, pp. 195-234.

Díaz Romero, Ma ${ }^{\text {a }}$ del R., "Extensión de la condición resolutoria explícita en la contratación inmobiliaria", en L. Dízz-PICAzo y Ponce de León, Revista Crítica de Derecho Inmobiliario (721) (2010), pp. 2281-2315.

Eidenmüller, H., Faust, F., Grigoleit, H. C., Jansen, N., Wagner, G., Zimmermann R., El marco común de referencia para el Derecho privado europeo. (Cuestiones valorativas y problemas legislativos), en ADC, 62 (4) (2009), pp. 1461-1522. 
Fernández Masiá, E., "Optando por la normativa común de compraventa europea”, en Revista Electrónica de Estudios Internacionales, 2012, pp. 1-21, en http://www.reei.org, fecha de consulta: 05 de mayo de 2013.

Gallego Domínguez, I., "La unificación del Derecho civil patrimonial europeo", en J. M. González Porras, F. P. Méndez González (coords.), Libro Homenaje al profesor Manuel Albaladejo García, t. I, Murcia, Colegio de Registradores de la Propiedad y Mercantiles de España, Servicio de Publicaciones de la Universidad de Murcia, 2004, pp. 1787-1810.

García Cantero, G., "La traducción española de la parte general del Código europeo de contratos", Ante la unificación europea del Derecho contractual: incidencia en España del Anteproyecto del Grupo de Pavia, s/f, en http://www.unizar.es, fecha de consulta: 17 de octubre de 2014.

García Pérez, R., "El incumplimiento anticipado o previsible (anticipated non performance) como incumplimiento resolutorio en la Propuesta de Modernización del Código Civil”, en R. Bercovitz Rodríguez-Cano, E. Rubio Torrano, BIB 2012 \3025, Revista Doctrinal Aranzadi Civil-Mercantil (7) (2012), pp. 1-27, en http://www.westlaw.es/, fecha de consulta: 2 de enero de 2014.

Gómez Calle, E., "Los remedios ante el incumplimiento del contrato: análisis de la Propuesta de Modernización del Código Civil en materia de obligaciones y contratos y comparación con el Borrador del Marco Común de Referencia”, en Ministerio de Justicia (Centro de Publicaciones) y Boletín Oficial del Estado (eds.), Anuario de Derecho civil, t. LXV, fasc. I, enero-marzo, Madrid, Librería del Boletín Oficial del Estado, 2012, pp. 29-102.

Gómez Gállico, J., "La repercusión en derecho español de las propuestas de armonización del Derecho Contractual Europeo”, en E. Bosch Capdevila, (dir.), Decanato del Colegio de Registradores de Cataluña (coord.), Derecho contractual europeo. Problemática, propuestas y perspectivas, Barcelona, Bosch, 2009, pp. 525-547.

Gómez Laplaza, Ma - del C. (coord.), Cuestiones sobre la compraventa en el Código civil. Principios europeos y Draft, Colección Monografias de Derecho Civil, II. Obligaciones, Madrid, Dykinson, 2012.

González Pacanowska, I., "Los principios Lando", en E. Bosch Capdevila (dir.), Decanato del Colegio de Registradores de Cataluña (coord.), Derecho contractual europeo. Problemática, propuestas y perspectivas, Barcelona, Bosch, 2009, pp. 151-182.

Herbosa Martínez, I., Veiga Copo, A. B., Cencerrado Millán, E., "El contrato de compraventa. La compraventa mercantil. El contrato de suministro”, en M. YzQUIERDo Tolsada (dir.), Contratos. Civiles, mercantiles, públicos, laborales e internacionales con sus implicancias tributarias, t. I, Contratos de finalidad traslativa de dominio, Navarra, Thomson Reuters (Legal) Limited, Aranzadi, 2014, pp. 619-714.

Jiménez Costa, A., "Libro II. Capítulos 1 y 2", en A. Vaguer Aloy, E. Bosch CapdeviLA, M. SÁnchez GonzÁlez (coords.), Derecho europeo de contratos. Libros II y IV del Marco Común de Referencia, t. I, Barcelona, Atelier Libros Jurídicos, 2012, pp. 95-182. 
Leible, S., "El Marco Común de Referencia y la elección del Derecho aplicable", en J. C. Fernández Rozas (dir.), Anuario español de Derecho internacional privado, t. VIII, Madrid, Marcial Pons, Ediciones Jurídicas y Sociales, 2008, pp. 481-492.

Leible, S., "Vías para la unificación del Derecho privado europeo", en Estudios monográficos, trad. de F. Infante Ruiz, en http://www.upo.es, fecha de consulta: 27 de febrero de 2015.

LLÁCER MatacÁs, Ma . R., "La garantía por falta de conformidad y el cumplimiento 'no conforme': el derecho español a la luz del Marco Común de Referencia”, en E. Bosch Capdevila (dir.), Decanato del Colegio de Registradores de Cataluña (coord.), Derecho contractual europeo. Problemática, propuestas y perspectivas, Barcelona, Bosch, 2009, pp. 461-474.

Medina Ortega, M., "El Derecho patrimonial europeo en la perspectiva del Programa de Estocolmo”, en J. C. Fernández Rozas (dir.), Anuario español de Derecho internacional privado, t. X, Marcial Pons, Ediciones Jurídicas y Sociales, Madrid, 2010, pp. 69-90.

Meli, M., "Proposta di Regolamento - Diritto comune europeo della vendita", en Le nuove legi civil commentate, anno XXXV, $\mathrm{n}^{\circ} 1$ gennaio-febbraio, Milano, Wolters Kluwer Italia S. R. L., Centro Direzionale Milanofiori, 2012, pp. 183-207.

Miláns del Bosch Portolés, I., "Cumplimiento e incumplimiento del contrato internacional”, en X. O'CALlaghan MuÑoz (coord.), Cumplimiento e incumplimiento del contrato, Madrid, Universitaria Ramón Areces, 2012, pp. 673-703.

Nanclares Valle, J., "Libro III. Obligaciones y derechos”, en E. Valpuesta Gastaminza (coord.), Unificación del Derecho patrimonial europeo. Marco Común de Referencia y Derecho español, Barcelona, Bosch, 2011, pp. 163-217.

Real Academia Española, Diccionario de la Lengua Española, t. I, 22 edición, México, Espasa Calpe, 2001.

Redondo Trigo, F., "De los Principios Lando al Marco Común de Referencia del Derecho Privado Europeo. Hacia un nuevo ius commune", en MinisTERIO DE JUSTICIA (Centro de Publicaciones) y Boletín Oficial del Estado (eds.), Anuario de Derecho civil, t. LXIII, fasc. IV, octubre-diciembre, Madrid, Librería del Boletín Oficial del Estado, 2008, pp. 1643-1682.

Rodríguez Marín, C., "La Propuesta de Anteproyecto de Modernización del Código Civil en materia de obligaciones y contratos. Diferencias y similitudes con el cumplimiento", en Consejo General del Notariado (ed.), Revista Jurídica del Notariado (76) (2010), pp. 271-300.

Rutgers, J. W., "Los contratos de agencia, franquicia y distribución en el DCFR", en E. Bosch Capdevila (dir.), Decanato del Colegio de Registradores de Cataluña (coord.), Derecho contractual europeo. Problemática, propuestas y perspectivas, Barcelona, Bosch, 2009, pp. 311-320.

SÁnchez LoREnzo, S., "La unificación del Derecho contractual y su problemática: la respuesta de la Unión Europea”, en E. Bosch CAPdevila (dir.), DecanATo DEL 
Colegio de Registradores de Cataluña (coord.), Derecho contractual europeo. Problemática, propuestas y perspectivas, Barcelona, Bosch, 2009, pp. 85-118.

Schulze, R., "El Acquis Communautaire y el Marco Común de Referencia para el Derecho contractual europeo”, en $\mathrm{M}^{\mathrm{a}}$. P. Ferrer Vanrell, A. Anselmo Cañellas (dirs.), Principios de Derecho contractual europeo y Principios de Unidroit sobre contratos comerciales internacionales, Actas del Congreso Internacional celebrado en Palma de Mallorca, Madrid, Dykinson, 2009, pp. 51-61.

Storme, M. E., "Good faith and contents of contracts in European private law", en Espiau Espiau S., Vaguer Aloy A. (eds.), Bases de un Derecho contractual europeo, Valencia, Tirant lo Blanch, 2003, pp. 17-30.

Valpuesta Gastaminza, E., "La propuesta de Derecho privado unificado de obligaciones y contratos para Europa: el Draft Common Frame of Reference", en E. VALPuesta Gastaminza (coord.), Unificación del Derecho patrimonial europeo. Marco Común de Referencia y Derecho español, Barcelona, Bosch, 2011, pp. 61-87.

Valpuesta Gastaminza, E., "El ámbito de regulación del futuro 'derecho contractual europeo'. De los principios sobre contratos comerciales a un derecho contractual general que incluya relaciones con consumidores", en E. Bosch CAPDEviLA (dir.), Decanato del Colegio de Registradores de Cataluña (coord.), Derecho contractual europeo. Problemática, propuestas y perspectivas, Barcelona, Bosch, 2009, pp. 405-418.

Vaguer Aloy, A., "El Marco Común de Referencia”, en E. Bosch Capdevila (dir.), Derecho contractual europeo. Problemática, propuestas y perspectivas, Barcelona, Bosch, 2009, pp. 239-265.

Vaguer Aloy, A., Bosch Capddevila, E., Sánchez González, Mà . P., "Prólogo", en A. VAguer Aloy, E. Bosch Capddevila, Ma . P. Sánchez González (coord.), Derecho europeo de contratos. Libros II y IV del Marco Común de Referencia, t. I, Barcelona, Atelier Libros Jurídicos, 2012.

von Bar, C., "A Common Frame of Reference for European Private Law-Academic Efforts and Political Realities", en V. V. Palmer (ed.), The Tulane European and civil law forum, vol. 23, New Orleans, Tulane University School of Law, 2008.

Zimmermann, R., “The Present State of European Private Law", en M. W. Reimann (ed.), The American Journal of Comparative Law 57 (2) (2009), pp. 479-512. 